\title{
Experimental Validation of a Likelihood-Based Stochastic Knock Controller
}

\author{
Andreas Thomasson, Haoyun Shi, Tobias Lindell, Lars Eriksson, Tielong Shen and James C. \\ Peyton Jones
}

\section{Linköping University Post Print}

\section{Tweet}

N.B.: When citing this work, cite the original article.

(C)2016 IEEE. Personal use of this material is permitted. However, permission to reprint/republish this material for advertising or promotional purposes or for creating new collective works for resale or redistribution to servers or lists, or to reuse any copyrighted component of this work in other works must be obtained from the IEEE.

Andreas Thomasson, Haoyun Shi, Tobias Lindell, Lars Eriksson, Tielong Shen and James C. Peyton Jones, Experimental Validation of a Likelihood-Based Stochastic Knock Controller, 2016, IEEE Transactions on Control Systems Technology, (24), 4, 1407-1418.

http://dx.doi.org/10.1109/TCST.2015.2483566

Postprint available at: Linköping University Electronic Press

http://urn.kb.se/resolve?urn=urn:nbn:se:liu:diva-130272 


\title{
Experimental Validation of a Likelihood-based Stochastic Knock Controller
}

\author{
Andreas Thomasson, Haoyun Shi, Tobias Lindell, Lars Eriksson, Tielong Shen, James C. Peyton Jones
}

\begin{abstract}
New likelihood-based stochastic knock controllers have the potential to deliver significantly improved regulatory response relative to conventional strategies, while also maintaining a rapid transient response, but evaluation studies to date have only been performed in simulation. In this paper an experimental validation of the new strategy is presented. To demonstrate the robustness of the method, the algorithm is implemented on two different engine platforms, using two different knock intensity metrics, and evaluated under different operating conditions. One of these platforms is a five cylinder variable compression ratio engine, enabling the controller to be tested under different compression ratios, as well as different speed and load conditions. The regulatory and transient performance of the likelihood-based controller is assessed in a back-to-back comparison with a conventional knock controller and it is shown that the new controller is able to operate closer to the knock limit with less variation in control action without increasing the risk of engine damage.
\end{abstract}

Index Terms-Automotive control, knock control, spark advance control, stochastic control.

\section{INTRODUCTION}

$\mathrm{T}$ HE output torque, fuel economy, and emissions from a spark ignition gasoline engine are strongly dependent on the phasing of the combustion process. Typically, these quantities improve as the spark timing is advanced towards Maximum Brake Torque (MBT), but they degrade sharply if the timing is advanced beyond the 'knock limit' where uncontrolled or 'knocking' combustion starts to occur, [1,2]. More importantly, perhaps, knocking combustion can be very damaging for the engine, particularly at high engine speeds, or simply an undesirable source of noise, vibration and harshness for the driver. The onset of knock depends on fuel quality, engine operating condition and other environmental variables, so some form of closed-loop knock control system is needed when operating in knock limited conditions. This requirement

Manuscript received XXXX. This work was supported in part by the Briar Hill Foundation and ExxonMobil.

A. Thomasson, L. Eriksson, and T. Lindell are with the Vehicular Systems Division, Department of Electrical Engineering, Linköping University, SE58183 Linköping, Sweden (e-mail: larer@isy.liu.se).

H. Shi and T. Shen are with the Department of Engineering and Applied Sciences, Sophia University, Japan (email: tetu-sin@ @offman.cc.sophia.ac.jp).

J. Peyton Jones is with the Center for Nonlinear Dynamics and Control and the Department of Electrical and Computer Engineering, Villanova University, Villanova, PA 19085 USA (e-mail: james.peytonjones@villanova.edu). is not new, and knock control has been an active topic of research for many years, but increasing demands for fuel economy and engine performance, together with the trend for heavily turbocharged, downsized engines (which are more susceptible to knock), have led to a renewed interest in the topic.

The literature on knock control is extensive, but focuses primarily on the knock sensing [3-5], and knock detection parts of the problem [6-14], (where 'knock detection' refers to the process of deriving some form of knock intensity metric from the knock sensor signal). The literature on the knock control strategy itself is much more sparse: A number of valuable contributions have been made [15-19], but the majority of production knock control systems still employ a conventional 'slow-advance, fast-retard' strategy. This strategy has a proven record for engine protection against engine damage but it operates at a mean spark advance which is significantly retarded relative to the desired BorderLine (BL) knock limit target, and therefore suffers some efficiency penalty. In a series of recent papers [20-26], the authors have advocated a new approach to knock control based on the fundamental binomial properties of knock events. Unlike the traditional controller which reacts deterministically to each knock event, the new controllers only adjust the spark when the statistical likelihood ratio of the observed knock events falls below some user-specified threshold. The controller therefore does not react unnecessarily when the control target is being met, but responds rapidly if it is not.

The results appear promising, with the controller able to operate slightly closer to the knock limit with reduced spark angle dispersion, while also retaining a fast transient response. However, these papers were based only on simulated data, and lacked experimental verification. The main contribution of this paper is therefore the experimental implementation and validation of the new control strategy. Preliminary results from this work were presented in [23], but this paper provides more detail. Furthermore, in this paper the robustness of the method is tested by implementing the strategy on two different engines, at two different institutions, and using two different metrics for quantifying knock intensity. One of these engines was a variable compression ratio engine, so it was also possible to test the algorithm at different compression ratios. Both steady-state and transient responses are evaluated and compared to the performance of a traditional knock controller.

The paper is organized as follows. Experimental details for the two different engine systems are presented in Section II. The knock characteristics of these engines are evaluated in Section III, based on an analysis of open-loop tests. The 


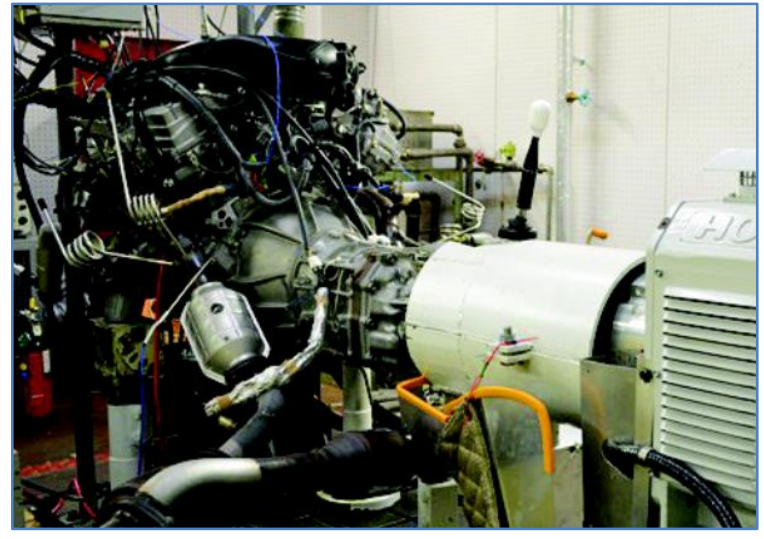

Fig. 1: Engine \#1: 6-cyclinder Toyota 3.51 engine

results are used to validate the assumption of statistical independence of the data, and also form the basis of the knock simulator used to test the controller prior to implementation on the real engine. Details of the conventional and likelihoodbased knock control algorithms are presented in Section IV, and a comparative evaluation of their steady-state and transient performance is given in Section V. Finally, brief conclusions are given in Section VI.

\section{EXPERIMENTAL SETUP}

As outlined in the Introduction, the experiments were performed independently on two different engines. The first was a six-cylinder 3.51 Toyota 2GR-FSE gasoline engine, 'Engine \#1', which was connected to a low inertial electric dynamometer on an engine test-bench (Fig. 1). The engine is naturally aspirated and there is no EGR. Inlet air temperature is not regulated, but depends on ambient conditions and operating point. Engine coolant, however, was controlled to $80^{\circ} \mathrm{C}$ using a PID controller to regulate the flow of water through an external heat exchanger. Knock sensing was by means of a production peizoelectric knock sensor from Toyota. The control algorithms were implemented on a dSPACE system which was connected to an otherwise standard ECU (taken from a 2010 Toyota Crown) via CAN Bus for overwriting the default control command for the spark advance. All other aspects of the engine control strategy, including Variable Valve Timing (VVT) control, were managed by the production ECU using its embedded proprietary strategy.The second set of experiments were performed on a prototype Saab Variable Compression (SVC) engine, 'Engine \#2'. This is a 5-cylinder 1.61 gasoline engine where the compression ratio can be varied from 8 to 14.5 , [27]. Figure 2 shows this engine connected to an electric dynamometer. Air intake is boosted with a mechanical compressor, and a bypass throttle is used to control the boost pressure. Valve timing is fixed, and there is no EGR. The engine has a water cooled intercooler, but intake manifold temperature is not directly controlled. As with Engine \#1, the testbed provides an external heat exchanger which is used to regulate the engine coolant temperature, in this case to $90^{\circ} \mathrm{C}$. The engine control system, consists of a MicroAutoBox connected to a RapidPro-system from dSpace. Knock sensing

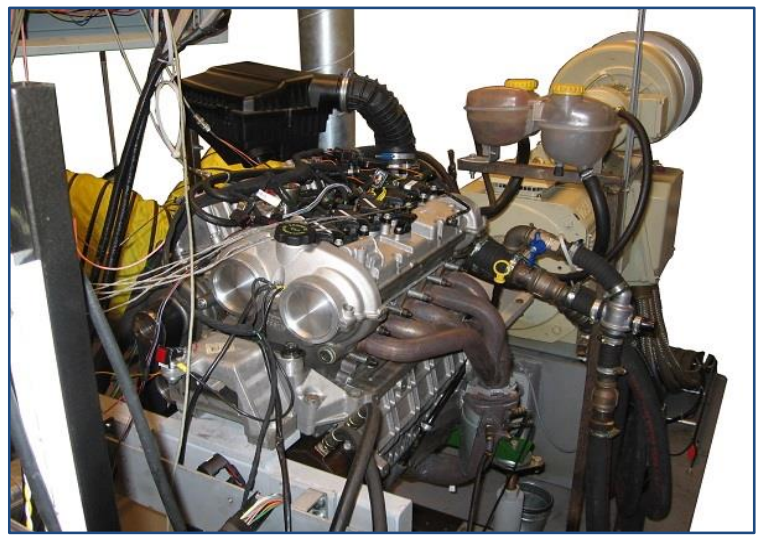

Fig. 2: Engine \#2, Saab Variable Compression

was again based on a production knock sensor (this time from Bosch). Cylinder pressure signals were used to help calibrate the knock sensors, but were not otherwise used or recorded during the study.

The tests on Engine \#1 were performed at $1200 \mathrm{rpm}$ and $1500 \mathrm{rpm}$ and $150 \mathrm{Nm}$ load respectively. Tests for Engine \#2 were performed across a broader range of conditions, including different compression ratios as well different speeds and loads, see Table 1. In common with many knock studies, high engine speeds were avoided because engine damage can occur much more rapidly in such cases. In all cases, the dynamometer control system was used to maintain the setpoint speed, and the nominal load was set by adjusting the throttle (or bypass throttle) manually. During testing, comparative tests were performed back-to-back to minimize the effect of drifting ambient conditions.

At each of the selected operating conditions, open-loop spark advance sweeps were performed in order to measure the knock characteristics of the engine - see Section 3. Closed loop experiments were also performed first using a standard knock controller to provide a baseline for comparison, and then using the new Likelihood-based knock controller. Finally, closed loop transient tests were performed in order to assess the response time of the controllers. In all cases, 2000 contiguous cycles of engine data were collected. Due to data acquisition limitations, the analysis of data from Engine \#1 focused on a single cylinder (arbitrarily chosen as cylinder \#5), while the analysis of data from Engine \#2 considered all cylinders.

TABLE I

Summary of operating points tested.

\begin{tabular}{cccc}
\hline Engine \# & CR [-] & Speed [rpm] & $\begin{array}{c}\text { Intake } \\
\text { Pressure } \\
{[\mathrm{kPa}]}\end{array}$ \\
\hline 1 & 11.8 & 1200 & 74 \\
\hline 1 & 11.8 & 1500 & 72 \\
\hline 2 & 12 & 1500 & 120 \\
\hline 2 & 12 & 1500 & 140 \\
\hline 2 & 14 & 1500 & 120 \\
\hline 2 & 12 & 1800 & 120 \\
\hline
\end{tabular}




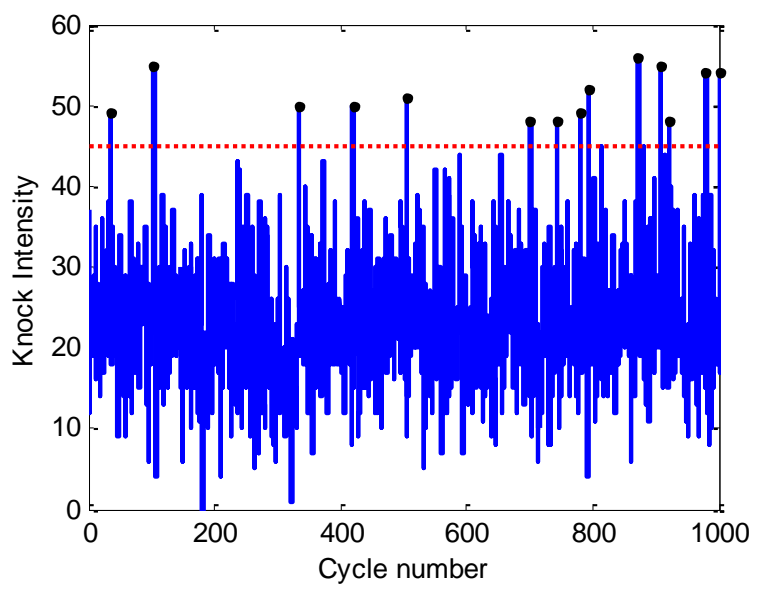

Fig. 3: Engine \#1: Knock Intensity versus cycle number (Cylinder \#5, 1500rpm, 150Nm load)

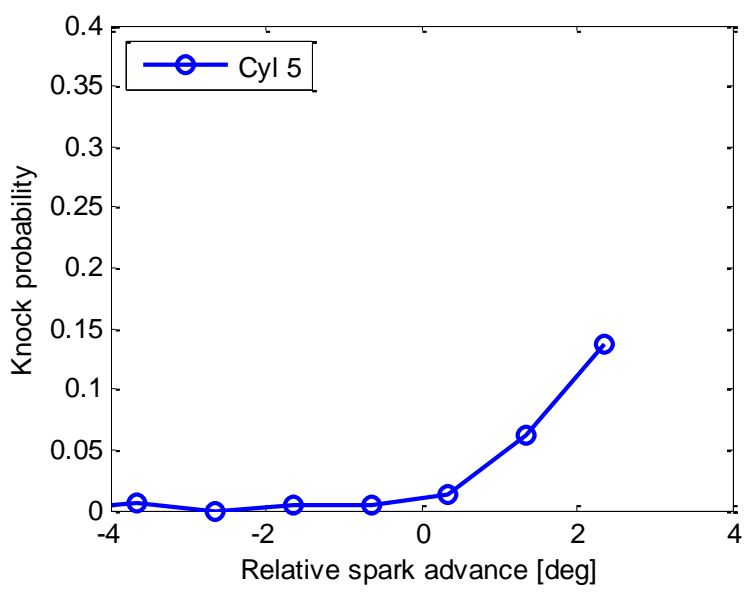

a) Engine \#1, cylinder \#5

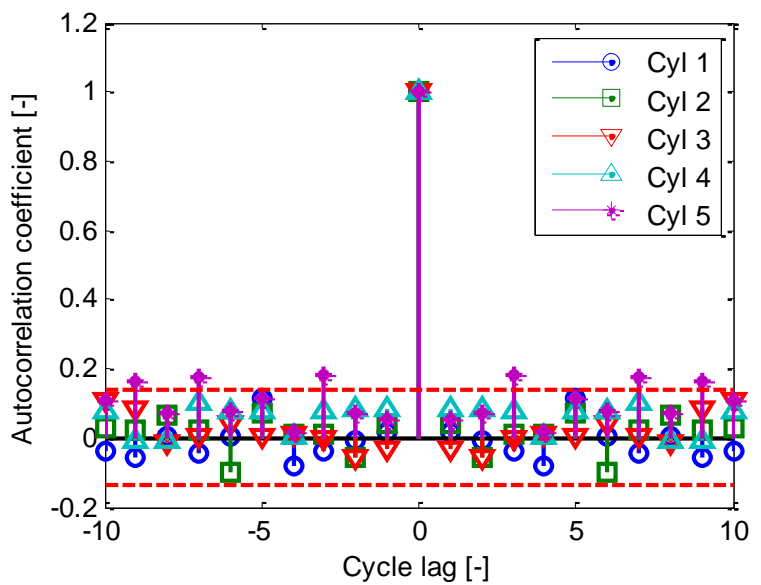

Fig. 4: Engine \#2: Autocorrelation of knock intensity $\left(\mathrm{BL}+4^{\circ}, 1500 \mathrm{rpm}, 120 \mathrm{kPa}\right.$ intake pressure $)$

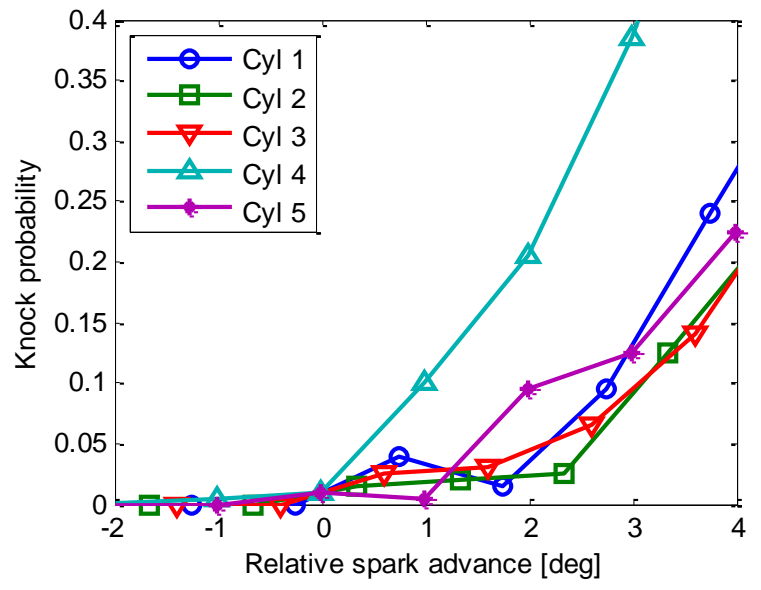

b) Engine \#2, All cylinders

Fig. 5: Knock probability as a function of spark advance relative to BL (1500 rpm)

\section{KNOCK CHARACTERIZATION}

Although all knock intensity metrics are, by definition, somehow related to the combustion / knock process taking place within the cylinder, the properties of these signals may vary depending on the knock sensor and knock detection algorithm employed. In this work, as mentioned above, production knock vibration sensors were used, but the processing of the vibration signal was different for the two engine platforms considered. On Engine \#1, the signal was first bandpass filtered around the knock resonant frequencies, and the logarithm of the peak voltage was defined as the knock intensity value. On Engine \#2, the signal was also filtered to select the knock resonant frequencies, but it was then rectified and integrated to obtain the knock intensity metric. These differences serve to provide some indication of the robustness of the control algorithm to the way in which knock intensity is defined, while at a more fundamental level it is interesting to examine the extent to which these differences affect the properties of the data. It is also useful to map the knock characteristics of the engine-plus-detectionalgorithm as a function of spark advance in order to serve as a basis for knock simulation and testing prior to final implementation of the knock control algorithm.

The statistical characteristics of these signals, and their variation with spark advance were therefore investigated using the open-loop spark sweep data described in Section 2. A plot of the time history of knock intensity versus cycle number is shown in Fig. 3. Although it is widely acknowledged that the process is random, it is also important to check whether the data is cyclically uncorrelated, [28]. A correlation analysis was therefore performed on the data from both engines based on 200 cycles of data. For Engine \#1, the correlation at all cycle lags (other than zero) was within the $\pm 95 \%$ probability interval expected for a white noise process. Typical results for Engine \#2, (Fig. 4), however, show that the cyclic correlation sometimes exceeds the $\pm 95 \%$ probability interval. Interestingly, the correlation at lags 3,4,5 often exceeded the correlation at lag 1, and in one data set (not shown) the lag 5 autocorrelation was as high as -0.33 . However, the prior cycle (lag 1) autocorrelation was generally within the probability interval, and the highest lag 1 outlier across all the data sets analyzed had a correlation coefficient of 0.25 . Examination of scatter plots and cylinder-to-cylinder correlations also showed 
no obvious trends. While it is possible that degree of cyclic or cylinder-to-cylinder correlation may increase at other conditions due to physical feedback mechanisms such as latent heat from extreme knock, high EGR, or valve timings that give high levels of residual gas, these results suggest that to a reasonable first approximation, the data behaves as a cyclically independent random process on both engine platforms considered. Such a conclusion is also consistent with a more extensive study of cyclic independence on a different engine across a large database of test results, [28].This is important because it means that the knock intensity of the forthcoming cycle is the outcome of an independent random event which by definition cannot be controlled directly. Standard control theory and methods therefore cannot be applied, and some form of stochastic control is necessary in order to control some statistical measure of the distribution from which knock intensities are drawn.

Although a variety of measures have been proposed, the most common and widely used practice is to apply a threshold, such as that shown in Fig 3, and to control the rate or probability of knock events that exceed this threshold value. Recent work has argued that the threshold level can be optimized in order to maximize the information fed back to the controller, and that this can significantly improve closedloop performance, [24]. However, in this work, following typical practice, the threshold is set such that a small number of cycles (1\%) classify as knocking at BorderLine (BL) knock conditions. The resulting 'hard' knock event rate can then be plotted as a function of spark advance, as shown for cylinder \#5 of Engine \#1, and all cylinders of Engine \#2, in Fig. 5. Note, the variable compression Engine \#2 has a special construction with a monoblock head so it was possible to drive the engine further into knock without risk of engine damage. Also note that for ease of comparison, these curves have been plotted with respect to the borderline spark angle for each engine / cylinder, and all the curves therefore have a $1 \%$ knock probability at $0^{\circ}$ relative to $\mathrm{BL}$ by definition. The absolute angle of 1\% BL knock varies slightly for each cylinder as shown in Table 2.

The knock probability characteristic of cylinder \#5, Engine \#1 (Fig. 5a) increases slightly more rapidly with spark advance, compared to all cylinders except cylinder \#4 of Engine \#2, (Fig. 5b). This may reflect slight differences in the underlying knock behavior of the different engines or may result from the different knock detection methods employed. The significant cylinder-to-cylinder variations observed in Fig. 5 b, however, clearly shows that some cylinders, (e.g. cylinder \#4 in particular), are significantly more prone to knock than other cylinders in the same engine. This could be due to differences in the soot load, or in fuel / air flow, or the result of some hotspot within the cylinder itself. Whatever their source, it is a simple matter to encapsulate these knock probability characteristics in a lookup table, and to use them as a basis for knock simulation. A simple knock simulator was constructed as shown in Fig. 6 and used to test the knock controller prior to implementation on the engine, - see also [26].
TABLE II

Absolute spark angle at Borderline Knock conditions (1500rpm).

\begin{tabular}{l|c|ccccc}
\hline Platform: & Engine \#1 & \multicolumn{5}{|c}{ Engine \#2 } \\
\hline Cylinder \# & 5 & 1 & 2 & 3 & 4 & 5 \\
\hline Borderline [deg] & 20.7 & 16.2 & 16.9 & 17.0 & 11.3 & 14.2 \\
\hline
\end{tabular}

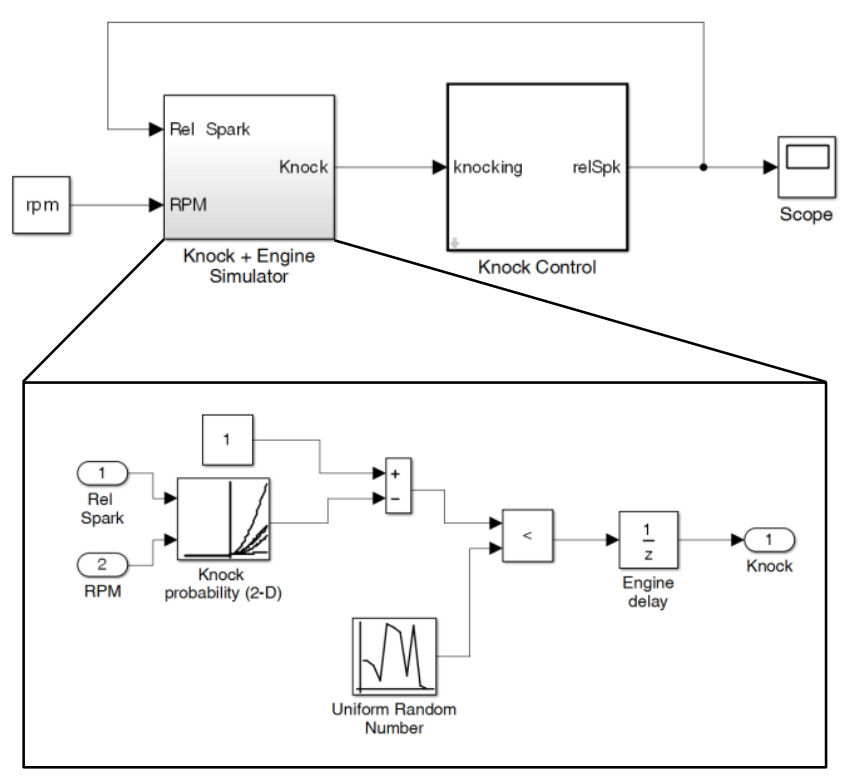

Fig. 6: Knock event generation and knock control simulation

\section{KNOCK CONTROL STRATEGIES}

\section{A. Conventional Knock Control}

Both the likelihood-based, and conventional control strategies investigated in this paper are stochastic event-based knock controllers in the sense that they respond to knock events (rather than knock intensity), and the control objective is to maintain a target knock event rate (e.g. 1\%) in spite of changes in engine operating and environmental conditions. However, the strategy used to achieve this knock rate target is very different in each case. A conventional controller, for example, slowly advances the spark $\theta(n)$ by an amount $K_{a d v}$ each non-knocking cycle, but rapidly retards the spark by a much larger amount $K_{\text {ret }}$ if a knock event occurs,

$$
\theta(n+1)= \begin{cases}\theta(n)-K_{r e t} & \text { if knocking } \\ \theta(n)+K_{a d v} & \text { otherwise }\end{cases}
$$

The resulting average knock rate, $p^{*}$, is determined by the ratio of the controller gains, since for stable limit cycle operation the advances must on average match the retards. This gives,

$$
K_{R \mathrm{e} t} p^{*}=K_{A d v}\left(1-p^{*}\right)
$$

and therefore,

$$
p^{*}=\frac{K_{a d v}}{K_{r \mathrm{e} t}+K_{a d v}} \quad K_{a d v}=\frac{p^{*}}{1-p^{*}} K_{r \mathrm{e} t}
$$




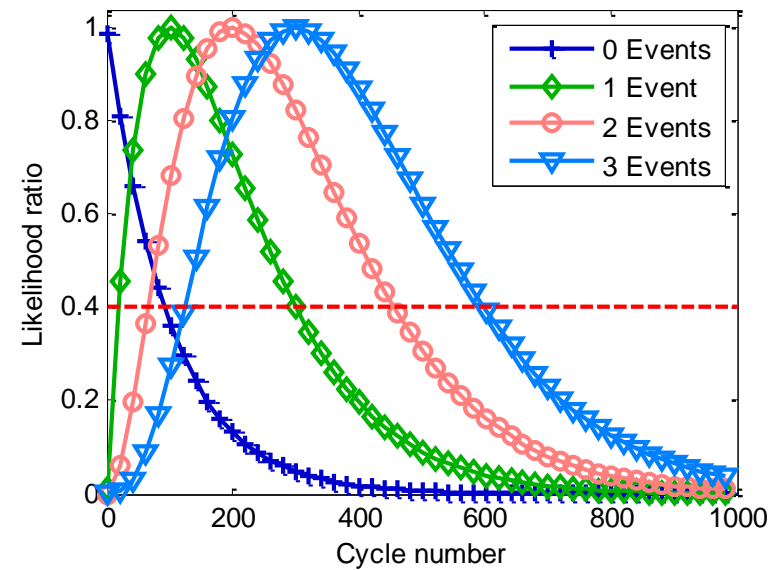

Fig. 7: Likelihood ratio as a function of cycle number, for different numbers of knock events $(p=0.01)$

Although this strategy is simple to implement and tune, the controller reacts deterministically to each knock event whether or not these knock events are occurring at the desired rate. This, and the fact that there is a control move every engine cycle, means that the controller is somewhat overactive resulting in a relatively wide dispersion of the closed-loop spark advance, and an inability of the controller to settle at the desired BL condition.

\section{B. Likelihood-based Knock Control}

The new likelihood-based knock controller is also an eventbased controller, but in this case the spark is only adjusted when there is statistical evidence that the knock rate target is not being met. Algorithmic details and theory have been presented in [22], but are briefly reviewed here for completeness. The approach is based on an assumption of cyclically independent knock events and on the observation that the binary classification of combustion cycles into knocking or non-knocking cycles means that knock events are, then by definition, binomially distributed. The probability of observing exactly $k$ knock events in $n$ cycles may therefore be written as,

$$
P_{n}(k, p)=\left(\begin{array}{l}
n \\
k
\end{array}\right) p^{k}(1-p)^{(n-k)}
$$

where $p$ denotes the knock probability at the current operating condition. The validity of (4) is strong from a theoretical perspective, but its use in this context also been validated against the distribution of knock events derived empirically from experimental data, as reported in [22]. The two were shown to be in excellent agreement, providing further confirmation of (4) as a basis for knock event-based analysis and controller design. It is straightforward, for example, to compute the ratio of the likelihood $P_{n}\left(k, p_{0}\right)$, evaluated using the target knock rate $p_{0}$, relative to the same likelihood $P_{n}\left(k, p_{\text {max }}\right)$, evaluated using the maximum likelihood estimate of the current knock probability $p_{\max }=(k / n)$. This likelihood ratio may therefore be expressed as,

$$
L_{n}(k)=\frac{p^{k}(1-p)^{(n-k)}}{p_{\max }^{k}\left(1-p_{\max }\right)^{(n-k)}}
$$

where, in limiting cases, $0^{0}$ is defined to be 1 . Likelihood ratios near unity indicate that the observed events are consistent with the knock rate target, while values that fall below some user-specified threshold suggest the opposite and that a spark adjustment is required. Furthermore, the magnitude of any adjustment can be scaled by a factor (1$L_{n}(k)$ ), so that the lower the likelihood ratio, the larger the compensating adjustment.

To illustrate this strategy, likelihood ratio curves are plotted as a function of cycle number, $n$, for different values of the number of observed knock events, $k$, in Fig. 7. Consider the curve for 2 knock events, for example, relative to a userspecified likelihood threshold $=0.4$, shown as a dotted red line in the figure. For an underlying $1 \%$ knock probability, one might expect 2 knock events in 200 cycles, and the curve peaks at this point. However, if the knock rate were truly $1 \%$ it would be quite unlikely to observe these two knock events within the first 64 cycles, or to observe only two knock events in the first 456 cycles. Indeed, since the likelihood ratio falls below the threshold at these points, a compensating spark adjustment would be triggered.

The algorithm is straightforward to implement in a real time control system. In its most basic form, the controller simply keeps count of the number of cycles, $n$, and number of knock events, $k$, that have occurred since the last spark adjustment. At each cycle, it uses these to evaluate first $p_{\max }=(k / n)$, and then the likelihood ratio $L_{n}(k)$ defined in (4) given also the target knock rate $p$. If the likelihood ratio falls below a userspecified thereshold, a control move of magnitude $K_{a d v} *(1-$ $\left.L_{n}(k)\right)$ is applied, and the counts of elapsed cycles and knock events are reset. Otherwise no adjustment is made, and the algorithm repeats at the next cycle.

Although this illustrates the basic principle of the algorithm, a complete pseudo-code listing is provided in the Appendix. This includes some additional details which are perhaps worthy of comment: In order to retain the alertness of the algorithm during long periods of steady operation, for example, the likelihood ratio is evaluated for each of the values of $n$ that correspond to the most recent history of 0,1 , 2 , or 3 knock events, looking backwards in time from the current cycle. If the likelihood ratio falls below the acceptable threshold in any of these instances, a spark adjustment is made, see [22] for further details.

The algorithm also includes two different 'fast advance' strategies in order to address an issue associated with a low (eg. 1\%) target knock rate. In this case, a large number of non-knocking cycles (approaching 100) must elapse before one can conclude that the actual knock rate is less than $1 \%$ and that a spark advance is necessary. Inspection of Fig. 7, for example, shows that 92 non-knocking cycles must be observed before the likelihood ratio falls below the threshold value of 0.4. This slows the recovery from overly retarded conditions. One solution to this difficulty is to lower the knock threshold and to work with a higher 'weak' knock rate target, [25]. In this work, however, two variants of a 'fast-advance' strategy 


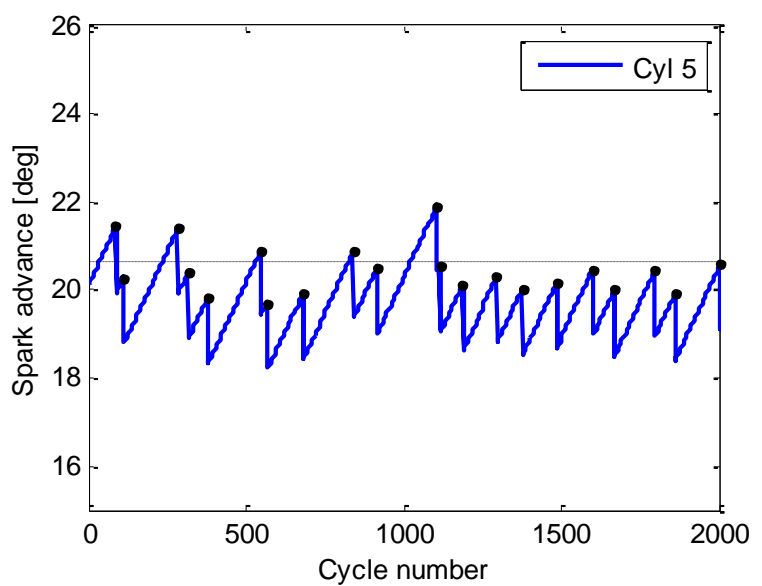

a) Engine \#1, cylinder \#5

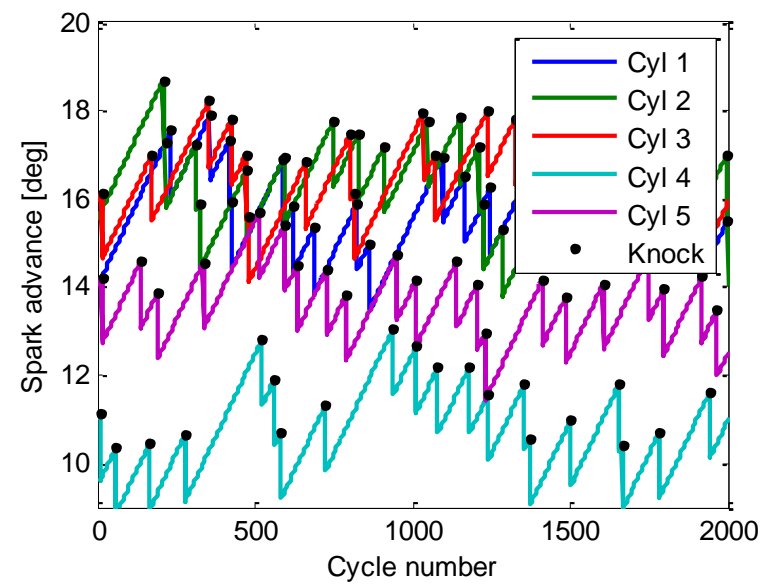

b) Engine \#2, All cylinders

Fig. 8: Closed loop spark advance time history using the conventional knock controller (1500 rpm)

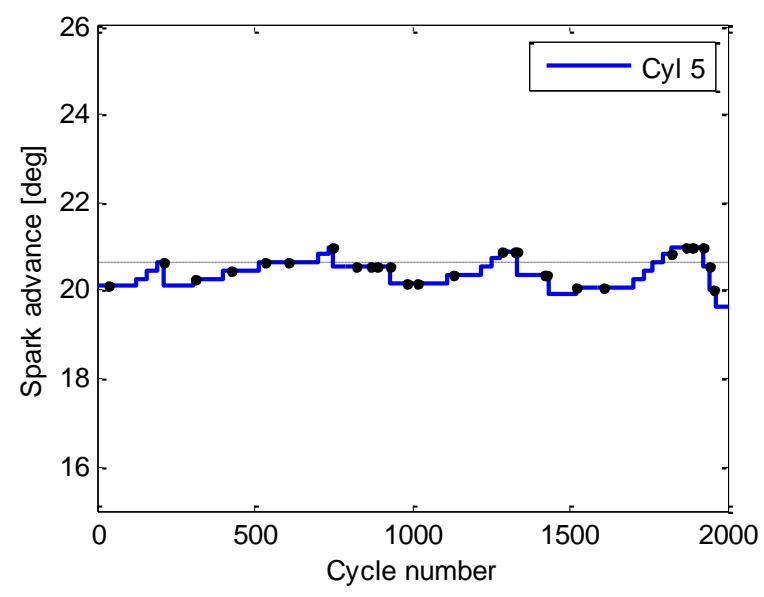

a) Engine \#1, cylinder \#5

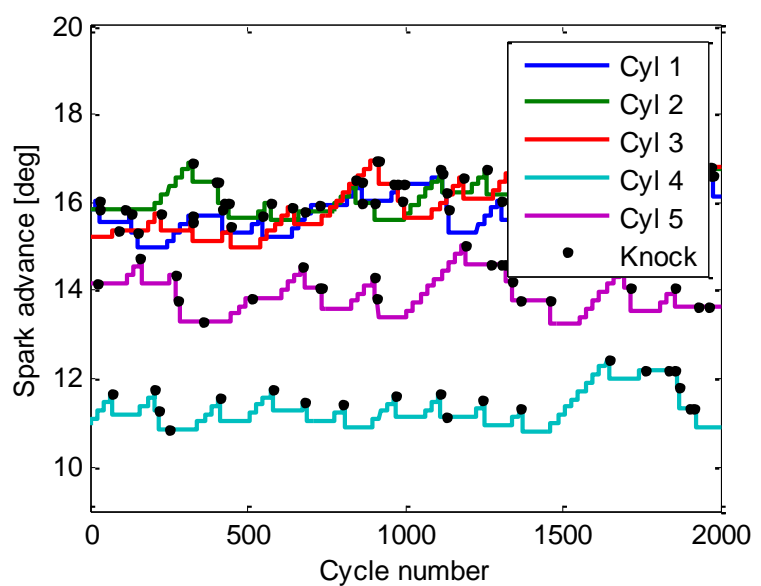

b) Engine \#2, All cylinders

Fig. 9: Closed loop spark advance time history using the likelihood-based knock controller (1500 rpm)

were implemented. In both cases, the system is made more sensitive to repeated "advance" events by resetting the cycle count $n$ to some positive number after an "advance" event, see [22] for further details. This speeds up the repeat advance response by reducing the number of cycles before the nonknocking likelihood ratio threshold is triggered. The response to knocking events, meanwhile, is minimally affected. In the second case, this strategy is extended by resetting the cycle count to a value which increases with the number of 'repeat advance' adjustments that have been made without the occurrence of a knock event, see [23] for further details. The reset cycle count is increased in three stages, after one, two and three spark advances with zero knock events, so that the rate of spark advance accelerates until the first knock event occurs.

\section{CLOSED-LOOP TEST RESUltS}

The conventional and likelihood-based knock controllers described above were implemented on each of the engine platforms described in Section 2. For the conventional strategy, the controller was tuned with a typical retard gain of $1.5^{\circ}$, and an advance gain of $K_{a d v}=1.5 / 99^{\circ}$, which according to (3), should yield a $1 \%$ target knock rate. For the likelihoodbased strategy, the parameters were (initially) simply chosen to be identical to the final tuning used in [22], namely: $p=$ $0.01, K_{a d v}=0.3, K_{r e t}=0.6$, and likelihood threshold $=0.4$. The first (non-accelerating) fast-advance strategy was used with a reset cycle count of 70 cycles. A series of steady-state and transient tests were then performed, initially at $1500 \mathrm{rpm}$, and the results are reported below.

\section{A. Steady-state Results}

The ideal response of a knock controller is to adjust the spark so as to settle as quickly as possible at the $\mathrm{BL}+0^{\circ}$ borderline knock condition where, from the steady-state tests of Section 3 , it has previously been established that a $1 \%$ knock rate is achievable. The actual closed-loop spark advance time histories, however, show significant deviations from this ideal. Fig. 8 a),b), for example, shows typical closed-loop time spark advance time histories for the conventional control strategy, plotted for cylinder \#5 of Engine \#1, and for all cylinders of Engine \#2, respectively. These traces show the classic sawtooth-like waveform associated with this type of controller, with the spark ramping up during knock-free periods, and retarding sharply every time a knock event occurs 


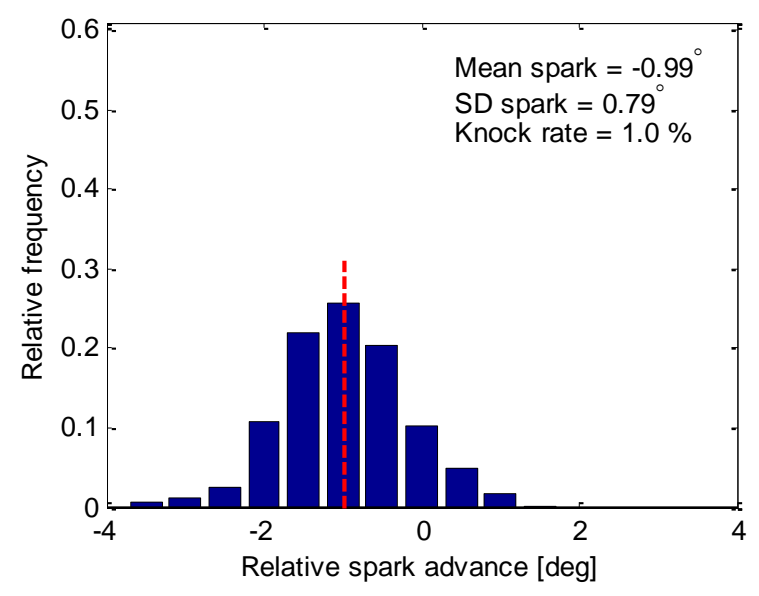

a) Engine \#1, cylinder \#5

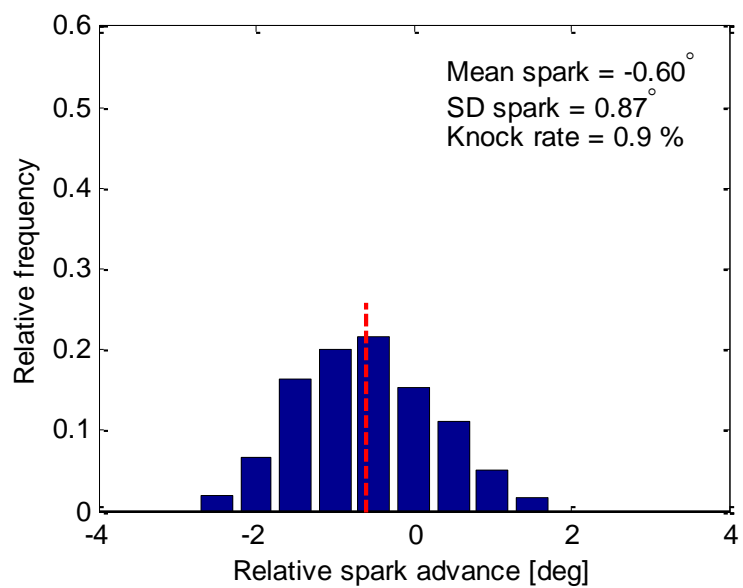

b) Engine \#2, cylinder \#1

Fig. 10: Histogram of closed loop spark advance using the conventional knock controller (1500 rpm)

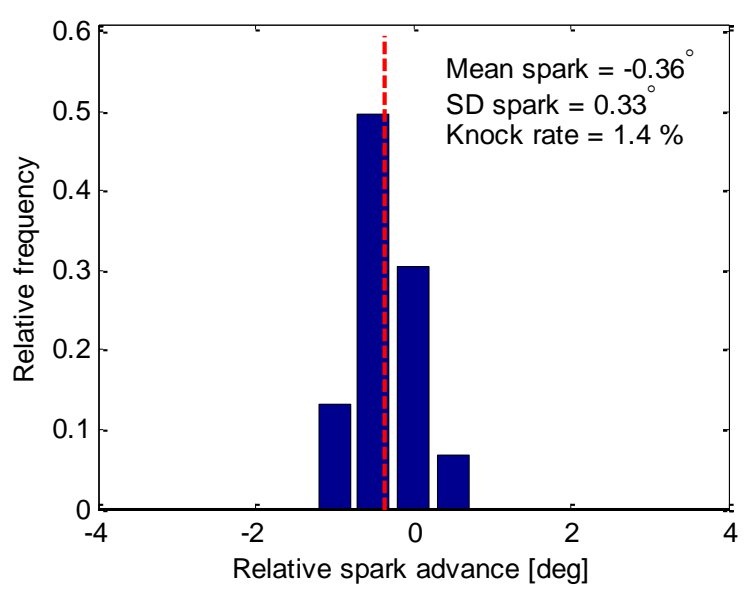

a) Engine \#1, cylinder \#5

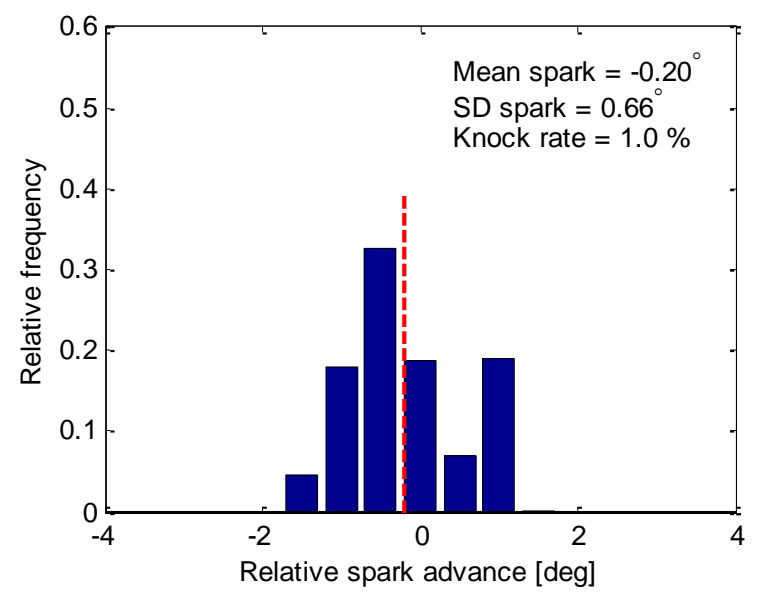

b) Engine \#2, cylinder \#1

Fig. 11: Histogram of closed loop spark advance using the likelihood-based controller (1500 rpm)

(as indicated by a small dot in the figure). It is also notable that the mean spark advance is significantly retarded with respect to the desired BL spark advance shown as a dotted line in Fig. 8a), or comparing the traces in Fig. 8b) with the BL spark values given in Table 2 .

The corresponding results for the likelihood-based controller are shown in Fig. 9 a),b). Note that knock events, indicated by small black dots in the figures, do not always result in spark adjustments, and the spark angle remains constant providing the likelihood of the observed knock events is consistent with the $1 \%$ knock rate target. However, if knock events occur in too quick succession, the controller still retards the spark rapidly, while if 'too few' knock events are observed, then the spark is advanced in a ramping step-like manner. These trends are observed on both engine platforms, though the closed loop response of Engine \#2 is more active than Engine \#1, suggesting some retuning is necessary (see below). In general, however, the likelihood-based controller is much less active than the traditional controller and remains closer to the desired BL knock condition identified in Table 2.

These differences are also apparent from histograms of the closed loop spark advance, shown in Figs. 10, and 11 respectively for each of the two controllers under test. The conventional controller, which continually cycles in and out of knock, results in a relatively wide dispersion in closed loop spark angle (Fig. 10). Although the closed-loop knock rate is controlled close to the desired $1 \%$ target, the mean spark advance is also significantly retarded relative to $\mathrm{BL}$, (by $1.0^{\circ}$ in the case of Engine \#1, and $0.6^{\circ}$ for Engine \#2). Note that the high level of dispersion, and the retarding of the mean spark are closely coupled to one another since the controller must compensate for the increased knock rate associated with the upper tail of distribution by retarding the mean spark advance relative to Borderline. The cyclic action of the controller also potentially exacerbates any inherent cyclic variability thereby degrading combustion stability.

In contrast, inspection of Fig. 11 shows that the likelihoodbased controller has a much lower degree of cyclic dispersion. For Engine \#1, for example, the standard deviation (SD) has been reduced by a factor of 2.4 , from $0.79^{\circ}$ using the conventional controller, to $0.33^{\circ}$ with the new controller. Similar, though less dramatic, results are seen for Engine \#2 (cylinder \#1), where the standard deviation of spark advance is reduced from $0.87^{\circ}$ to $0.66^{\circ}$. In the case of Engine \#1, the 


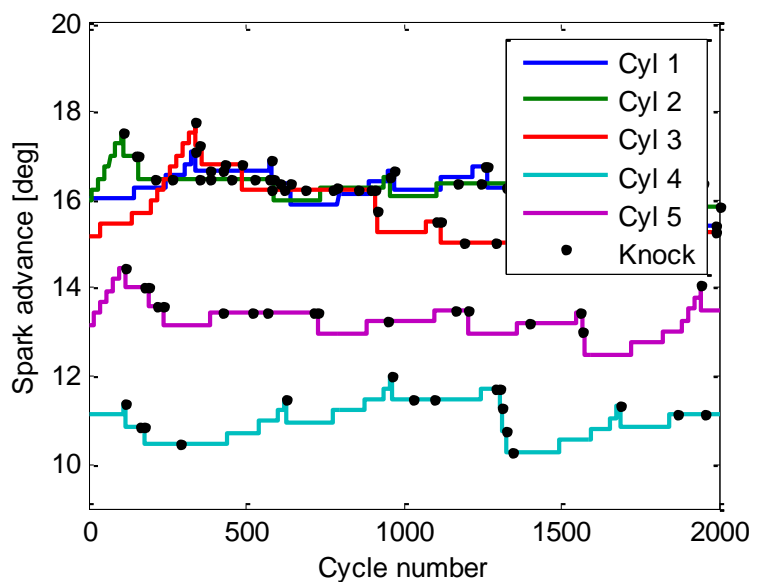

Fig. 12: Engine \#2, Closed loop spark advance time history using the re-tuned likelihood-based knock controller and 'accelerating' fast advance strategy (1500 rpm)

reduced dispersion is also accompanied by a significant $\left(0.63^{\circ}\right)$ increase in the mean spark advance, although the achieved knock rate $(1.4 \%)$ is slightly above target. In the case of Engine \#2 (cylinder \#1), the improvement in mean spark advance is more modest (increasing from BL- $0.6^{\circ}$ to BL- $0.2^{\circ}$ ), but the achieved knock rate, $1.0 \%$, matches the specified target very accurately.

Despite these improvements, it is noticeable that the time histories of Fig. 9 b) in particular still iterate somewhat about the BL condition, and never settles for long at a constant value. One reason for these iterations is that at a $1 \%$ knocking condition there should be on average 100 cycles between knock events, but with the likelihood threshold set at 0.4 the controller will begin to advance the spark after 92 nonknocking cycles. The controller for Engine \#2 was therefore slightly retuned, by reducing the likelihood threshold to 0.35 . This also has the effect of making the controller less responsive generally, so the gains were increased slightly to compensate $\left(K_{a d v}=0.3, K_{r e t}=0.6\right)$, and the 'accelerating' fastadvance strategy was implemented. The results, shown in Figs. 12, 13, show a further improvement in closed-loop stability $\left(\mathrm{SD}\right.$ of spark advance $\left.=0.36^{\circ}\right)$, and a more significant $\left(0.56^{\circ}\right)$ improvement in mean spark angle, similar to that achieved on Engine \#1.

The steady state performance of the controller was also tested at a number different operating conditions as described in Section 2, and the results collated and compared to the standard controller as shown in Table 3. One difficulty compiling this table was drift in the nominal BL condition, so where possible comparison tests were performed back-toback. However, this drift was particularly apparent in Engine $\# 1$, and is likely the cause of the $1200 \mathrm{rpm}$ result (annotated) which is otherwise physically inconsistent with both the steady-state mapping tests, and the closed loop likelihood controller tests. [It should not be possible to operate at a more advanced spark condition, and with more cyclic variability, and yet achieve a lower knock rate].

With these caveats, the results show that the likelihood based controller is able to operate closer to the desired $\mathrm{BL}$

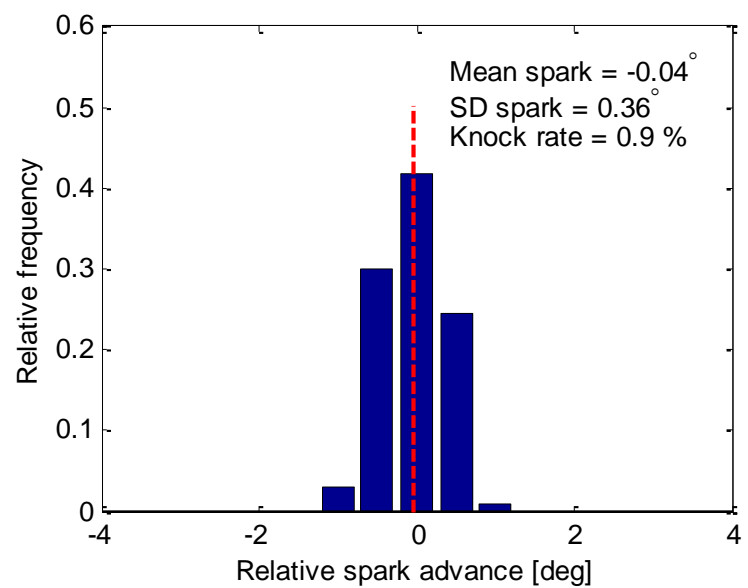

Fig. 13: Engine \#2, Histogram of closed loop spark advance using the retuned likelihood-based controller and 'accelerating' fast advance strategy $(1500 \mathrm{rpm})$

condition with reduced cyclic dispersion. With no specific tuning or calibration of the controller, the likelihood-based strategy successfully maintained the knock rate to within $0.4 \%$ of the target; the mean spark angle was slightly improved by $0.2-1.0^{\circ}$ relative to the conventional controller, and the standard deviation of closed-loop spark angle was reduced by $25-60 \%$. With minor retuning of the controller on Engine $\# 2$, there was a slight improvement in the accuracy of the achieved closed-loop knock rate and the standard deviation of closed-loop spark angle was in some cases reduced still further. The largest benefits were observed at higher speed or compression ratio, perhaps due to differences in the knock probability characteristic. A steeper knock probability characteristic, for example, is likely to lead to stronger coupling between reductions in closed-loop spark dispersion and improvements in the mean spark advance.

TABLE III

Steady-state Knock Controller performance

(Engine \#1, cylinder \#5; Engine \#2 cylinder \#1).

\begin{tabular}{|c|c|c|c|c|}
\hline $\begin{array}{l}\text { Engine / } \\
\text { Condition }\end{array}$ & Algorithm & $\begin{array}{c}\text { Knock } \\
\text { Rate } \\
{[\%]} \\
\end{array}$ & $\begin{array}{c}\text { Mean } \\
\text { Spark } \\
{[\mathrm{BL} \pm \text { deg] }} \\
\end{array}$ & $\begin{array}{c}\text { SD } \\
\text { Spark } \\
\text { [deg] }\end{array}$ \\
\hline $\begin{array}{l}\text { Engine } \# 1, \mathrm{CR}=11.8 \\
74 \mathrm{kPa}, 1200 \mathrm{rpm}\end{array}$ & $\begin{array}{l}\text { Conventional } \\
\text { Likelihood }^{1} \\
\end{array}$ & $\begin{array}{l}1.0 \\
1.5 \\
\end{array}$ & $\begin{array}{c}+0.17^{*} \\
-0.19\end{array}$ & $\begin{array}{l}0.71 \\
0.49 \\
\end{array}$ \\
\hline $\begin{array}{l}\text { Engine } \# 1, \mathrm{CR}=11.8 \\
72 \mathrm{kPa}, 1500 \mathrm{rpm}\end{array}$ & $\begin{array}{l}\text { Conventional } \\
\text { Likelihood }^{1}\end{array}$ & $\begin{array}{l}1.0 \\
1.4\end{array}$ & $\begin{array}{l}-0.99 \\
-0.36 \\
\end{array}$ & $\begin{array}{l}0.79 \\
0.33\end{array}$ \\
\hline $\begin{array}{l}\text { Engine } \# 2, C R=12 \\
120 \mathrm{kPa}, 1500 \mathrm{rpm}\end{array}$ & $\begin{array}{c}\text { Conventional } \\
\text { Likelihood }^{1} \\
\text { Likelihood }^{2}\end{array}$ & $\begin{array}{l}0.9 \\
1.0 \\
0.9\end{array}$ & $\begin{array}{l}-0.60 \\
-0.20 \\
-0.04 \\
\end{array}$ & $\begin{array}{l}0.87 \\
0.66 \\
0.36 \\
\end{array}$ \\
\hline $\begin{array}{l}\text { Engine } \# 2, C R=12 \\
140 \mathrm{kPa}, 1500 \mathrm{rpm}\end{array}$ & $\begin{array}{c}\text { Conventional } \\
\text { Likelihood }^{1} \\
\text { Likelihood }^{2} \\
\end{array}$ & $\begin{array}{l}1.0 \\
1.1 \\
1.1 \\
\end{array}$ & $\begin{array}{c}-0.6 \\
-0.42 \\
-0.29 \\
\end{array}$ & $\begin{array}{l}0.97 \\
0.35 \\
0.53 \\
\end{array}$ \\
\hline $\begin{array}{l}\text { Engine } \# 2, C R=14 \\
120 \mathrm{kPa}, 1500 \mathrm{rpm}\end{array}$ & $\begin{array}{l}\text { Conventional } \\
\text { Likelihood }^{1} \\
\text { Likelihood }^{2}\end{array}$ & $\begin{array}{l}1.0 \\
1.4 \\
0.7\end{array}$ & $\begin{array}{l}-0.88 \\
-0.29 \\
-0.01\end{array}$ & $\begin{array}{l}0.90 \\
0.49 \\
0.36\end{array}$ \\
\hline $\begin{array}{l}\text { Engine } \# 2, C R=12 \\
120 \mathrm{kPa}, 1800 \mathrm{rpm}\end{array}$ & $\begin{array}{l}\text { Conventional } \\
\text { Likelihood }^{1} \\
\text { Likelihood }^{2}\end{array}$ & $\begin{array}{l}0.9 \\
1.0 \\
1.1\end{array}$ & $\begin{array}{c}-1.0 \\
-0.01 \\
-0.25\end{array}$ & $\begin{array}{l}1.12 \\
0.55 \\
0.63\end{array}$ \\
\hline
\end{tabular}

"This result may be biased by drift in the BL condition

${ }^{1} p_{0}=0.01, K_{a d v}=0.3, K_{\text {ret }}=0: 6, \mathrm{LT}=0: 4, k_{0}=\{0,70,70,70\}$

${ }^{2} p_{0}=0.007, K_{\text {adv }}=0.4, K_{\text {ret }}=0.6, \mathrm{LT}=0.35, k_{0}=\{0,50,90,130\}$ 


\section{B. Transient Results}

Although the steady-state results of section 5.A are important from the perspective of improved fuel economy, it is equally important that the controller has a fast transient response, and returns to the steady-state condition quickly if perturbed by some change in the underlying knock rate. Such changes in the knock rate can be triggered by changes in engine operating condition as well as changes in fuel quality or other environmental conditions. In many cases, changes in operating condition are accompanied by other feed-forward control actions from the engine management system, so it is hard to identify the performance of the knock controller in isolation. Furthermore, it should be cautioned that any experimental result depends upon the particular realization of the knock random process that happened to occur during the experiment. Repeating the experiment under identical conditions may give a different result, simply due to the different arrival of random knock events, [26].

With these caveats, several transient experiments were performed to provide at least an indication of the responsiveness of the two controllers under test. In the first case, disturbances were generated artificially by first adding, then removing a $1.6^{\circ}$ offset to the spark advance commanded of the engine. The controller should respond by adjusting the controller output such that the spark advance commanded of the engine is restored as rapidly as possible to its prior steadystate mean value.

The result of applying this test to the conventional controller on Engine \#1 is shown in Fig. 14 a). The controller is initially operating around its mean spark advance of BL$1.0^{\circ}$ when at cycle number 782 the $+1.6^{\circ}$ disturbance is applied. The controller rejects this disturbance rapidly, making an initial large correction on the $5^{\text {th }}$ cycle after the disturbance was applied, although it does not actually return to BL conditions until 38 cycles have elapsed (see inset to Fig. 14 a)). The controller then continues to cycle about the BL condition although there appears to be a slow trend of advancing spark timing during the disturbance offset period. The controller is therefore in a relatively advanced state when the disturbance is removed at cycle number 1558 , so the results do not really show the response of the controller to an overly retarded transient condition. For a conventional controller, however, the advance response is defined precisely by the advance gain, which is 0.015 degrees per cycle in this case.

The response of the likelihood-based controller to a similar test is shown in Fig.14 b). In this case the spark angle is initially fairly stable near the desired BL condition. The disturbance, applied at cycle number 783 , results in a sudden $+1.6^{\circ}$ spike as the controller quickly returns the spark to its steady state condition. As seen from the inset in Fig. 14 b), the controller makes an initial (relatively small) correction only 3 cycles after the disturbance is applied. This is followed by several further adjustments, finally returning to the predisturbance BL condition 19 cycles after the disturbance was applied.
At cycle number 1544 the disturbance is removed, leaving the controller in a retarded state. At first sight, the subsequent advance response of the likelihood controller seems very slow, failing to regain the BL condition in the 445 cycles before the end of the experiment. However, the slow response is at least partly attributable to four knock events that happened to occur even though the engine was operating in a retarded condition. These events signal to the controller the need to stop advancing, and even to retard the spark still further.

To make a fair assessment of the advance rate of a controller, it is necessary to observe the response in the absence of knock events. As illustrated in the experiment, this is hard to prescribe experimentally, but the advance rates in the absence of knock are defined absolutely by the algorithm code. As noted above, the advance rate of the conventional controller is simply the value of the advance gain, $K_{a d v}=0.015$ degrees per cycle. In the case of the likelihood based controller, there is an initial period of 92 cycles before advances are triggered, and advances of approximate magnitude $0.3^{*}(1-0.4)=0.18^{\circ}$ then occur every $(93-70)=23$ cycles, i.e. at a rate of 0.0078 degrees per cycle. The likelihood-based controller therefore advances at a rate approximately half that of the conventional controller. While this represents a degradation of the advance transient response, it is considered an acceptable penalty to pay for the improved steady state performance, especially since the likelihood-based controller spends much less time on average advancing and retarding the spark compared to the cycling behavior of the conventional controller. It should also be noted that the slow rate of advance is a by-product of the low (1\%) target knock rate used in this study. With such a low target rate, it is necessary to wait for many non-knocking cycles before there is sufficient evidence that the knock rate is below target. Recent work [29] suggests that this problem may be considerably alleviated by lowering the knock detection threshold and controlling to a correspondingly higher 'weak knock' rate target.

A more physically-based transient test was applied to Engine \#2 by performing a tip-in experiment with a step from $100 \mathrm{kPa}$ to $140 \mathrm{kPa}$ intake manifold pressure. The transient was performed with feedforward control action disabled in order to highlight the speed of the feedback response. The results, for the conventional and likelihood-based knock controllers are shown in Fig. 15 a), b) respectively. Both controllers are similar with respect to the number of cycles required to reach the new operating point, but the conventional controller has fewer knock events during the transient. The reason for this is that the conventional controller can retard by an amount $K_{\text {ret }}=1.5^{\circ}$ on each knock event, whereas the likelihood controller can only retard by a maximum of $K_{\text {ret }}=$ $0.6^{\circ}$ at each control move. This difference has little impact if the required spark adjustments are relatively small. In this experiment, however, because the feedforward terms are disabled, there is no feedforward adjustment of the base spark timing, and the knock controller therefore has to deliver an unrealistically high adjustment of the order of $10^{\circ}$ or more. Thus, while it might be possible to adapt the algorithm so as to 


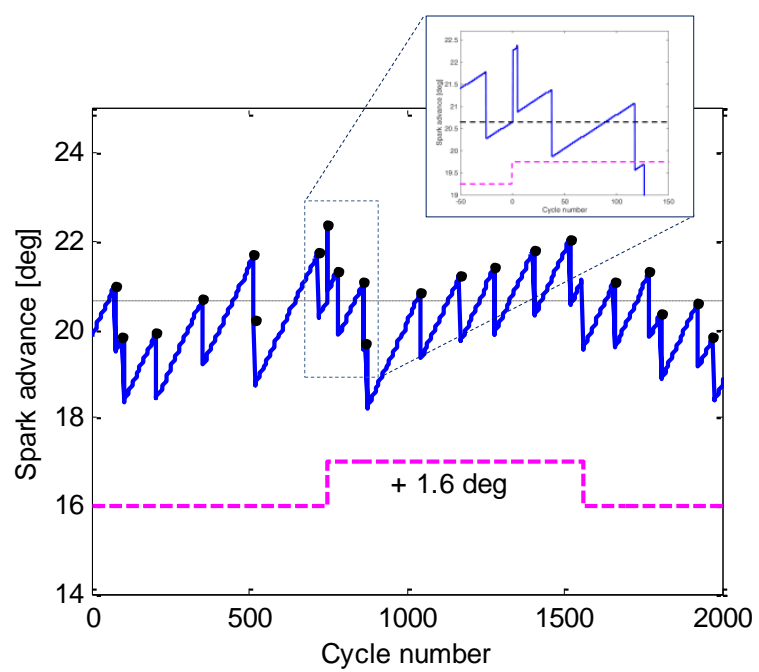

a) Conventional controller

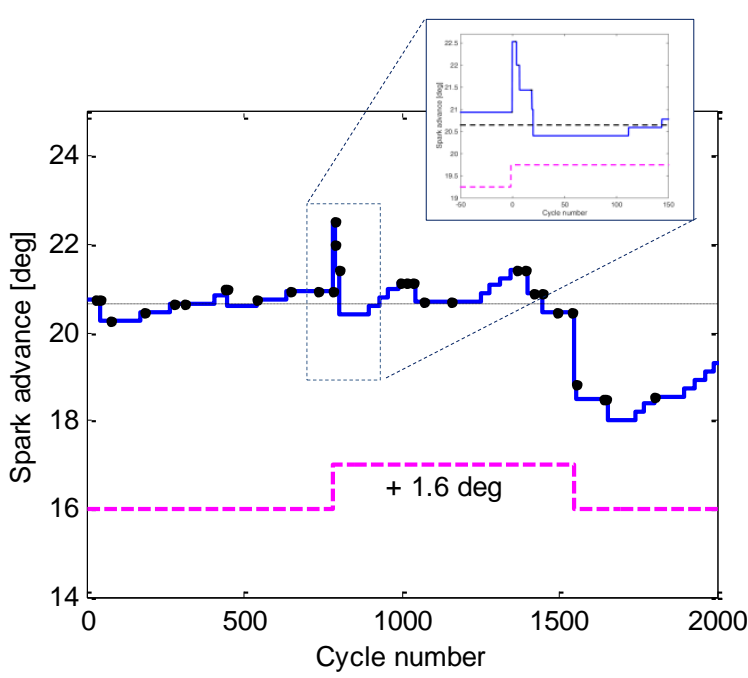

b) Likelihood-based controller

Fig. 14: Engine \#1, Transient closed loop spark advance time history in response to a $+1.6^{\circ}$ spark angle disturbance (Cylinder \#5, $\left.1500 \mathrm{rpm}\right)$

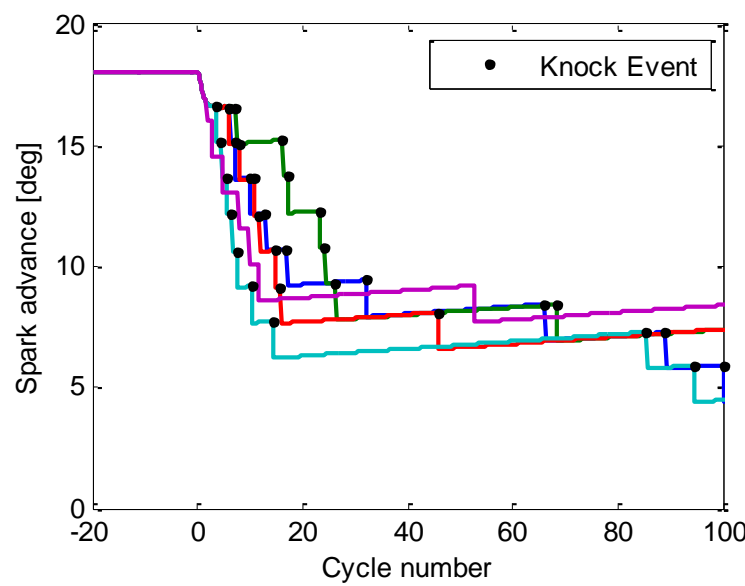

a) Conventional controller

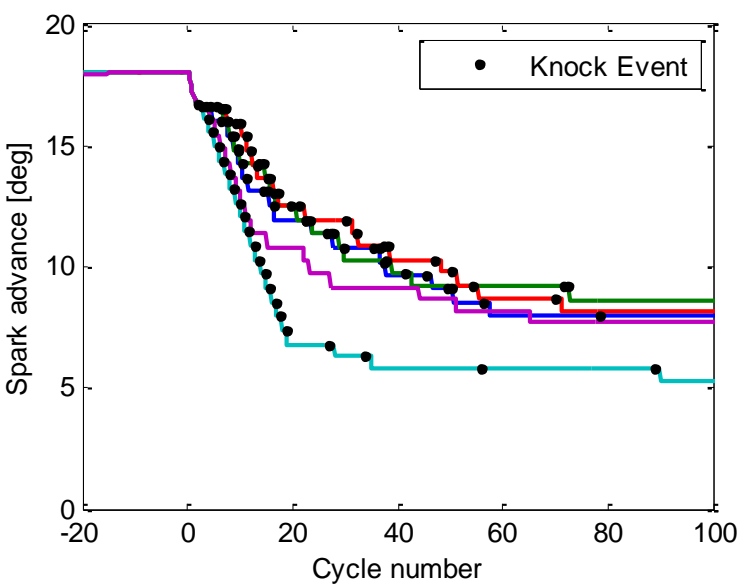

b) Likelihood-based controller

Fig. 15: Engine \#2, Transient closed loop spark time history in response to a tip-in event from $100 \mathrm{kPa}$ to $140 \mathrm{kPa}$ intake manifold pressure, with no feedforward adjustment of the base spark timing (all cylinders).

increase the magnitude of the control action on repeat knock events, it is unlikely that this issue will arise on a production system.

\section{CONCLUSION}

A likelihood-based knock controller has been implemented in a real-time control system and tested on two different engine platforms at two different institutions. In general, the algorithm has been shown to perform well while also being robust to differences in engine knock characteristics and operating conditions, as well as to differences in the way in which the knock intensity metric is computed on each engine platform.

For both engines, an experimental evaluation of the steadystate performance of the new controller confirms previous simulation results, and demonstrates that the stochastic controller can operate with a more optimal spark and reduced spark angle cyclic variability compared to the conventional controller. The new controller is also seen to have a fast transient response to overly advanced / high knock rate conditions, retarding the spark back to BL on a timescale similar to that of the conventional controller. The transient response to overly retarded conditions or an absence of knock events is slower, (approximately half that of the conventional controller). Although this is undesirable, the slower advance rate carries no increased risk of engine damage, and could be considered an acceptable tradeoff for the improved steady state performance. It should also be noted that the controller spends much less time on average advancing and retarding the spark compared to the cycling behavior of the conventional controller. An 'accelerating' fast advance strategy, together with slight retuning of the controller gains has been shown to further reduce cyclic variability on Engine \#2.

While this work demonstrates improvements in knock spark timing control, the effects of these changes on engine fuel economy, emissions, and cyclic variability of the combustion process itself, have not been assessed. In future work it is hoped to obtain a quantitative comparison of the two knock 
control strategies with respect to these end goals, both by running the strategies over standard drive cycles, and by analysis of cylinder pressure data. It is also hoped to obtain a more rigorous evaluation of transient performance through a combination of engine tests and stochastic simulation, and to use this to compare the performance of the likelihood controller to other advanced controllers that are based on different knock metrics and strategies. Finally, it is hoped to improve the transient advance response of the likelihoodbased controller, possibly by exploiting recent results which suggest that performance can be improved by optimizing the knock threshold used to define knock events.

\section{REFERENCES}

[1] L. Eriksson, "Spark advance modeling and control," Ph.D. dissertation, Linköping Univ., Linköping, Sweden, 1999.

[2] Proceedings of the International Symposium on Knocking of combustion engines, 26-27 November 1981, Volkswagen, Wolfsburg.

[3] S. Dues, J. Adams, and G. Shinkle, "Combustion knocking sensing sensor selection and application issues," SAE paper 900488, 1990.

[4] U. Orleans, L. Vinci, "Limitations of ionization current sensors and comparison with cylinder pressure sensors," SAE paper 2000-01-2830.

[5] Abhijit, J.D. Naber, "Ionization signal response during combustion knock and comparison to cylinder pressure for SI engines," SAE paper 2008-01-0981.

[6] K.P. Schmillen and M. Rechs, "Different methods of knock detection and knock control," SAE paper 910858, 1991

[7] X. Gao, R. Stone, C. Hudson and I. Bradbury, "The detection and quantification of knock in spark ignition engines," SAE paper 932759, 1993.

[8] T. Horner, "Knock detection using spectral analysis techniques of a Texas Instruments tms320 DSP," SAE paper 960614, 1996.

[9] B. Samimy and G. Rizzoni, "Engine knock analysis and detection using time-frequency analysis," SAE paper 960618, 1996.

[10] D. Scholl, T. Barash, S. Russ, and W. Stockhausen, "Spectrogram analysis of accelerometer-based spark knock detection waveforms," SAE paper 972020, 1997.

[11] F. Millo, C.V. Ferraro, "Knock in S . I . Engines : A Comparison between Different Techniques for Detection and Control," SAE paper 982477, 1998.

[12] G. Brecq, J. Bell;ettre, and M. Tazerout, "A new indicator for knock detection in gas SI engines," Int J Thermal Sciences, 42(5), pp.523-532, 2003.

[13] J. Naber, J. Blough, D. Frankowski, M. Goble, and J. Szpytman, "Analysis of combustion knock metrics in spark-ignition engines," SAE paper 2006-01-0400, 2006.

[14] A.J. Shahlari, J.B. Ghandhi, "A Comparison of Engine Knock Metrics," SAE paper 2012-32-0007, 2012.

[15] Y. Ham, K. Chun, J. Hyung, and K. Chang, "Spark-ignition engine knock control and threshold value determination," SAE paper 960496, 1996.

[16] M. Pennese, A. Bucci, F. Damasceno, and G. Montanari, "Sigma ® on knock phenomenon control of flex fuel engines," SAE paper 2005-013990, 2005.

[17] N. Cavina, G. Po, and L. Poggio "Ion current based spark advance management for maximum torque production and knock control," in Proc. Eighth Biennial ASME Conference on Engineering Systems Design and Analysis, pp. 537-545, 2006.

[18] G. Zhu, I. Haskara, and J. Winkelman, "Stochastic limit control and its applications to spark limited control using ionization feedback," in Proc. 2005 American Control Conference, pp. 5027-5034, 2005.

[19] Stotsky, A. "Statistical engine knock model and adaptive control," Proc IMechE, Part D: J. Auto. Eng., 222(3): 429-438, 2008, doi:10.1243/09544070JAUTO707.

[20] J. C. Peyton Jones, J. Frey, K.R. Muske, and D. Scholl, "A Cumulativesummation-based stochastic knock controller," Proc. IMechE, Part D: J. Automobile Engineering, 224(D7), 969-983, (2010), DOI 10.1243/09544070JAUTO1505.
[21] J. Peyton Jones, J. Frey, and K. Muske, "A statistical likelihood based knock controller," in Proc. 6th IFAC Symposium Advances in Automotive Control, Munich, Germany, 2010.

[22] J. Peyton Jones, J. Spelina, and J. Frey, "Likelihood-based control of engine knock," IEEE Transations on Control Systems Technology, 21(6), pp.2169-2180, 2013.

[23] Thomasson, A., Eriksson, L., Lindell, T., Peyton Jones, J., et al., "Tuning and experimental evaluation of a likelihood-based engine knock controller," Proc $52^{\text {nd }}$ IEEE Conference on Decision \& Control, Italy, December 10-13, 2013.

[24] Peyton Jones, J.C., Spelina, J.M., and Frey, J. “Optimizing Knock Thresholds for Improved Control,” Int J. Engine Research, 2013, doi: $10.1177 / 1468087413482321$.

[25] J.C. Peyton Jones, J.M. Spelina, and J. Frey, “An optimal CumSumbased Knock Controller," Proc. 7th IFAC Symposium on Advances in Automotive Control, Sep 4-7, Tokyo, Japan, 2013.

[26] J. Spelina, J.C. Peyton Jones, and J. Frey, "Recent Advances in Knock Analysis, Simulation, and Control," SAE paper 2014-01-1349

[27] H. Drangel, E. Olofsson, and R. Reinmann, "The variable compression (SVC) and the combustion control (SCC)-two ways to improve fuel economy and still comply with world-wide emission requirements," SAE Paper 2002-01-0996, 2002.

[28] J.M. Spelina, J.C. Peyton Jones, and J. Frey, "Characterization of knock intensity distributions, Part I: statistical independence and scalar measures," Proc. IMechE Part D: Journal of Automobile Engineering, 228(2), pp.117-128, 2014. doi:10.1177/0954407013496233.

[29] Peyton Jones, J. C., Spelina, M., Frey, J., (2013), An Optimal CumSumbased Knock Controller, 7th IFAC Symposium on Advances in Automotive Control, Sep 4-7, Tokyo, Japan, 2013. 


\section{APPENDIX}

Pseudocode for Likelihood-based knock control, including accelerating advance strategy.

Initialize Knock Event Counter $K E C=0$;

Initialize FIFO buffer for cycle counts $k=\{0,0,0,0\}$;

Initialize Spark Advance Counter $S A C=0$

Initialize Cycle count after spark advance $k_{0}=\left\{0, n_{1}, n_{2}, n_{3}\right\}$;

...

If $\{$ knocking $\}$

$K E C=\min (K E C+1,3)$;

$S A C=0$;

Right-shift the FIFO buffer by one place, (left-fill with 0 );

\section{EndIf}

For $\{i=0$ to $K E C$. $\}$

$k(i)=k(i)+1$;

$p_{\text {max }}=K E C / k(i)$;

If $\{i=0\}$

Compute likelihood ratio: $L=L_{0}\left(k(0)+k_{0}(S A C)\right)$

Else

Compute likelihood ratio: $L=L_{i}(k(i))$

\section{EndIf}

If $\{L<L T\}$

If $\left\{p_{\max }<p_{0}\right\}$

Increment spark by $K_{a d v}(1-L)$;

$S A C=\min (S A C+1,3)$;

Else

Decrement spark by $K_{\text {ret }}(1-L)$;

$S A C=0$;

EndIf

$K E C=0$;

$k=\{0,0,0,0\}$;

\section{EndIf}

\section{EndFor}

